DOI 10.37882/2500-3682.2021.03.01

\title{
ОСНОВНЫЕ ТЕОРЕТИЧЕСКИЕ ПОДХОДЫ К ИЗУЧЕНИЮ КНИЖНОЙ КУЛЬТУРЫ
}

\section{BASIC THEORETICAL APPROACHES TO STUDYING BOOK CULTURE}

\section{A. Asfandiyarova}

Summary: Interest in the study of trends in the development of book culture in the scientific community has been growing in recent years. The digitalization of reading is changing the vector of development of modern book culture. Understanding the perspectives of this movement is important, but it is impossible without attention to the history of the study of the issue.

The purpose of the article was to determine the main conceptual approaches to the study of book culture, which became the forerunners of those modern studies that are actively conducted in science today. The author used methods of analysis and critical assessment of sources, identified and systematized the main approaches to the study of book culture, knowledge about which is already available in science. Understanding them can become the foundation for the formation of a new methodological toolkit and a theoretical approach that will allow us to study the current state of book culture and identify trends for possible future transformations.

Keywords: book culture, book, book business, culture, scientific approach.
Асфандиярова Альфия Рашитовна

Аспирант, Башкирский государственный педагогический университет им. М. Акмуллы cbs-direktor@mail.ru

Аннотация: Интерес к изучению тенденций развития книжной культуры в научной среде в последние годы растет. Цифровизация чтения изменяет вектор развития современной книжной культуры. Понимание перспектив этого движения важно, но оно невозможно без внимания к истории изучения вопроса.

Целью статьи стало определение основных концептуальных подходов к изучению книжной культуры, ставших предтечей тех современных исследований, которые активно ведутся в науке сегодня.

Автором использованы методы анализа и критической оценки источников, определены и систематизированы основные подходы к изучению книжной культуры, знание о которых уже имеется в науке. Понимание их может стать фундаментом для формирования нового методологического инструментария и теоретического подхода, который позволит исследовать современное состояние книжной культуры и выявить тенденции возможных будущих трансформаций.

Ключевые слова: книжная культура, книга, книжное дело, культура, научный подход.

Сам термин «книжная культура» долгое время не использовался как научный, чаще применялся для характеристики книжного дела на определенном этапе развития общества в историческом ключе, а также для объединения в один ряд большого числа явлений, имеющих отношение к книге или литературе. Фактически как научное понятие начал получать свое определение только в 21 веке. Даже в энциклопедии под названием «Книга» [13], вышедшей в 1999 году в научном издательстве «Большая российская энциклопедия» под редакцией видных ученых-книговедов не отведено отдельной статьи по теме «Книжная культура». То же можно сказать и об энциклопедическом словаре «Книговедение» [14].

Однако употребление термина в научных статьях 20 века мы находим довольно часто. При этом фундаментальные концепции по изучению самого явления, на наш взгляд, уже сложились задолго до определения понятия, иногда даже без фактического упоминания термина, ввиду того, что вопросы распространения и функционирования книги в обществе интересуют ученых с давних пор и по сути раскрывают сущность книжной культуры. Следует сделать оговорку, что наша систематизация не претендует на «всеохватность» и выявление всех имеющихся подходов, а ставит целью аккумулировать нако- 
пленные знания о теоретических подходах к изучению книжной культуры и условно выделить общие тенденции в этом направлении.

Одним из ведущих научных подходов к изучению книжной культуры можно назвать культурно-историческое (или культурно-мемориальное [12; 34]) направление, развивающееся в рамках аксиологического подхода в культурологических и филологических традициях. Оно связано с изучением книжных памятников старины, редких и рукописных книг, частных книжных собраний, книгопечатания и книгоиздания того или иного периода русской истории. Ученые этого направления подчеркивают уникальную роль книги в системе культуры, исследуют феномен преимущественно в ретроспективном ключе в традициях классической русской филологии и часто ограничиваются изучением конкретного книжного памятника. Сторонники направления определяют книжность в этическое поле, а книжную культуру характеризуют как проявление высокой культуры, как неоспоримую ценность и выражение нравственного духа личности, народа, эпохи, основным способом интеллектуального развития считая чтение [20; 95-99].

У истоков этого направления стояли такие видные ученые-филологи, философы и культурологи, как Ф.И. Буслаев [6], А.Ф. Лосев [18], Д.С. Лихачев[17], С.С. Аверинцев[1]. В книгах, сотворенных много веков назад, они видели первоисточник современной культуры и говорили о необходимости изучения книжной культуры и истории книги в контексте эпохи, истории языка, истории общественной мысли и истории культуры. Каждый памятник литературы и культуры рассматривался под пристальным вниманием как уникальное творение и зеркало отраженной в нем философии эпохи и самой эпохи. Внимательно вглядываясь в литературное произведение, в его язык и поэтику, композиционную структуру и смысловое содержание ученые понимали общие законы поэтики текстов древних книжных памятников, таким образом формировали представление о книжной культуре эпохи и об уровне развития культуры эпохи в целом. Академик Д.С. Лихачев писал: «История книги, если ее рассматривать широко, контекстно, а не только как историю книжного оформления, чрезвычайно важная часть истории культуры человечества»[16; 10]

О взаимосвязи книги и культуры определенно высказывался и М.Н. Куфаев, видный ученый, книговед, который сам был библиофилом-коллекционером и считал сохранение редких памятников книжности и культуры одной из существенных сторон своей деятельности. Находясь под влиянием идей Г. Риккерта и позитивизма, ученый, безусловно, подходил к анализу книги и книжного дела также с позиций аксиологического подхода.

М.Н. Куфаев определял книгу как «источник культурной жизни в настоящем и через настоящее в прошедшем и будущем» и в форме вопроса: «Разве нельзя мысленным взором не только видеть, но и ощущать всеединство книги как «субъекта» культуры и жизни или как живого фактора ее?» - он подчеркивал неразрывную связь книги и культуры [15; 22]. Доказывая необходимость ее изучения «философски», т.е. со стороны «идеальной», утверждал, что «философия книги» должна выяснить принципы, «определяющие с одной стороны ее бытие и развитие, с другой ее познание» [15; 23], понять в чем природа и сущность этого феномена. Книга его интересовала и как исторический культурный артефакт, и «как социальный факт культуры», и как «индивидуальный продукт человеческой психики» [15; 37], т.е. выделяя двойственную природу книги, при этом он обосновал идею необходимости философского осмысления и теоретического исследования книги и «книжного процесса». Этот подход к изучению книги и книжной культуры мы можем назвать, вслед за В.Л. Бениным, Р.А. Гильмияновой и Р.А. Жуковой, философско-культурологическим [5; 37].

Особенная задача М.Н. Куфаева - обращение к изучению читателя и чтения. Для ученого книга существует лишь потому, что она создана для читателя и содержит мысли, предназначенные именно для него. Познание природы и сущности книги может происходить только «в динамике читательского процесса», «на пути ее проникновения к читательскому окружению» [15; 56]. Изучение читателя, читательского восприятия книги, читательской среды ученый считал одной из важнейших задач науки, а интерес к теме «книга - читатель», стремление осмыслить конечную фазу этого процесса - читательскую подводило его по сути к пониманию сущности книжной культуры.

Убеждение, что книга «живет» в тесной взаимосвязи с обществом, являясь сама «фактором жизненного процесса» и человеческой культуры, несомненно, фактически приводило М.Н. Куфаева к определению длинной цепи «жизни книги». Он выделил те факторы, которые сопутствуют развитию книжной культуры, отнеся к ним состояние культуры, степень умственного и нравственного развития и образования общества и личности, исторический момент, личность автора, издателя, торговца, политическое состояние государства и общества, степень насыщенности книжного рынка, состояние торговли и промышленности, емкость рынка (количество типографий, издательств), состояние книгопечатания и техники, историческую традицию, состояние и развитие устного и печатного слова. Этот подробный перечень факторов и говорит о том, что М.Н. Куфаев, анализируя сущность книги, несомненно, говорил о ее органичном существовании в обществе, выявляя как внутренние ее жизненные процессы, так и обусловленные общественным влиянием [15; 25].

Внимание к личности читателя характеризует и концепцию известного книговеда, создателя теории книги 
и библиопсихологии Н.А. Рубакина. Этот подход к изучению книжной культуры мы назовем «читателеориентированным». Ученый понимает термин «книга» очень широко, включая в него не только множество различных документов, но даже и устную речь. Его логика состоит в том, что «книга нередко начинается в виде разговора, который затем систематизируется, записывается и таким образом кристаллизуется то в рукописную, то в печатную речь». Он приближает понятия «книга», «литературное произведение» и «документ» и утверждает, что отношение специалиста, работающего с книгой должно исходить с точки зрения «читательства».

Рубакин много говорит об изучении процесса распространения и «циркуляции книг», в своем интереснейшем исследовании «Этюды о русской читающей публике» [25; 35-104] сравнивает ситуацию в России и в других странах и, приходя к неутешительным оценкам, делает вывод о необходимости достижения основной цели - довести книги до читателя так, чтобы они были восприняты, поняты и приняты. Он выделяет очень важный, на наш взгляд, тезис, непосредственно касающийся развития книжной культуры в обществе: «Быстрое обращение книг - одно из самых необходимых условий быстрого обращения идей» [25; 101]. Также он особо говорит о влиянии произведения на личность читателя, для которого книга не просто передатчик авторских переживаний, а прежде всего возбудитель собственных. Читатель читает то, что откликается на его душевное состояние, на его переживания, но необходимо найти эффективные способы общения с читателем, а значит, основная задача библиопсихологии - исследование читателя, его взаимоотношений с автором и книгой, поиск этих способов «доставки» книг до читателя. Он изучает интересы и желания читателей, занимается проблемами организации библиотек, которые хочет видеть лабораториями изучения общественного мнения в отношении книги. До Н.А. Рубакина мало кто из ученых так серьезно подходил к вопросу изучения читательских интересов, восприятия читателем книги и ее влияния на человека. Этот подход сегодня формирует один из приоритетных аспектов в исследованиях книжной культуры и имеет перспективы для своего развития.

В начале 20 века в изучении книжной культуры появилось направление, сформировавшееся в рамках семиотической концепции, выдвинутой Ф. де Соссюром, и рассматривающее книгу как знаковую систему. Этот подход можем назвать также «текстовым». Согласно этой теории, книга - это система знаков, включающих слово, предложение, язык и идентифицируется с текстом. Эта концепция стала определяющей для тартуско-московской школы, связанной прежде всего с именами Ю.М. Лотмана, Б.А. Успенского и идеей вторичных моделирующих систем. Семиотический подход расширяет рамки книжной культуры, выявляя новые качественные связи между книгой и ее потребителем, который дол- жен уметь «прочитать» ее культурный текст и разгадать культурный код, зашифрованный в смысловой канве, что позволяет этому «потребителю» оказаться в поле культурных смыслов. Книжная культура дает возможность трансформировать «память», создает такое соотношение «литературы» и «жизни», благодаря которому в сопоставлении с реальностью раскрываются потаенные смыслы текстов, дающие возможность переделать прошлое, потом пережить это скоррегированное прошлое как истинную реальность [19]. Вопросы взаимовлияния и диалога в пространстве текста культуры неразрывно связаны с книжной культурой, а книга - и инструмент, и главный действующий герой этого процесса.

Близка к этому и концепция, разработанная М.М. Бахтиным, и представляющая в основе человеческого общества - диалог (процесс коммуникации). Тогда книжная культура предстает как знаковое общение, как процесс обмена текстуально оформленной смысловой информацией, в котором роли авторов и читателей становятся не просто условными, но и взаимопроникающими, многоголосие культурных текстов предполагается наличием самораскрывающихся смыслов. Полифоничность культурных текстов расширяет роли субъектов культурного поля, предлагая в процессе коммуникации услышать разные позиции. И этот диалог обеспечивает взаимопонимание. «Только диалогическая установка помогает принимать чужое слово всерьез», а внутренний диалог реализуется в процессе культурной коммуникации в поле книжной культуры, основным универсальным термином которой, по мысли Бахтина, также, как и у ученых тартуско-московской школы, является текст [3]. Эта идея будет отправной точкой для многих исследователей книжной культуры и позднее.

Информационно-коммуникативный (документологический) подход к изучению книжной культуры был очень распространен в нашей стране и базировался на исследованиях видного бельгийского ученого, основателя Международного библиографического института в Брюсселе Б.П. Отле, который определил такие понятия как «книга», «документ» и «документация» в одном ряду синонимов в качестве терминов, обозначающих носитель социальной информации и знаний «по любому предмету в любой области знаний». П. Отле также напрямую не использовал термин «книжная культура», но его взгляды на книгу, которая являет собой не только сосредоточение мысли, но и «сбор идей и их распространение» дают нам право говорить о своеобразном подходе к изучению книжной культуре: «Книги сделались органами хранения, сосредоточения и распространения мысли, и надо смотреть на них, как на орудия исследования, культуры, обучения, осведомления и отдыха. Они являются одновременно средством сбора идей и средством их распространения» $[22 ; 49]$.

П. Отле уже в начале 20 века искал новые форматы 
книг, был убежден, что они будут появляться, старался доказать, что формат книги не влияет на ее возможность передавать информацию, более того, считал, что изображения будут доминировать над письменным текстом, и это будет иметь огромное влияние на модернизацию книги. И здесь главным для него было сохранение культурной памяти. «Книги, разумея под этим общим названием всякого рода рукописные и печатные произведения, написанные или изданные в форме отдельных книг, периодических журналов, художественных изданий - в числе многих миллионов - представляют в своей совокупности материализованную память человечества, в которой день за днём регистрируются поразившие ум человека факты, идеи, деяния, чувства, мечты, каковы бы они ни были» [22; 49].

Обобщающее понятие «книги-документа» П. Отле предлагал употреблять для обозначения всего массива документов - рукописных и печатных, сюда же включая и журналы, газеты, графические репродукции, чертежи, карты, схемы, диаграммы, даже фотографии и гравюры, записи голоса с помощью фонографии, диапозитивы, кинематографические фильмы и т.д. Такая «книга», отмечает Воскресенский А.К. [8; 279], анализируя вклад П. Отле в науку о книге и документоведение, обозначалась как орудие для общения индивидов и носитель научной информации, причем особое внимание уделялось документации как источнику создания «единого мира знаний открытого доступа».

Эта идея позднее найдет свое отражение в науке о книге, будет развиваться и поддерживаться отечественными книговедами второй половины 20 века и даже позднее и получит выражение в системно-типологическом подходе, характеризующимся многочисленными изысканиями книговедов относительно типологии книги. В исследованиях А.А. Беловицкой, А.А. Гречихина, С.П. Омилянчука, Г.Н. Швецовой-Водки, А.В. Соколова, Ю.Н. Столярова и др. книга начинает осознаваться как научная категория. Предметом изучения становится книга как разновидность документа, носитель социально-значимой информации и форма функционирования знания. Книга - документ, создаваемый в результате деятельности коммуникационного посредника (книгоиздательской или редакционно-издательской организации) и попадающий к получателю информации в виде знаковой системы в результате деятельности коммуникационного посредника (учреждений системы книгораспространения и книгоисполъзования) [30; 259]. В рамках этого подхода сегодня идет научное определение и понятия «электронная книга».

Определение книжной культуры как научного термина становится предметом изучения подхода, который мы условно назовем социально-коммуникативным. Базовую основу данного подхода заложили труды известных книговедов Н.М. Лисовского, А.М, Ловягина, а также уже упомянутых выше Н.А. Рубакина, М.Н. Куфаева.

Н.М. Лисовский, разрабатывая методики систематизации книговедческих объектов и создавая типологические модели для всего многообразия реально существующих в обществе книг, которые возможно было бы применить ко всем типам и видам книг, предложил широко распространенную впоследствии формулу: «книгопроизводство - книгораспространение - книгоописание» [4]. Эту формулу «дополнил» Рубакин, предложив свою триаду: «автор - книга - читатель», в которой прослеживается линия интереса к читателю, т.е. «книгопотреблению», таким образом в этих формулировках фактически выстроилась теоретическая модель системы книжной культуры в обществе. А.М. Ловягин [4], одним из первых в отечественном книговедении осознавший необходимость учета социальной и коммуникативной природы книги и книжного дела, которую поддержал и М.Н. Куфаев и добавил к общей теоретической картине книжной культуры, определив длинную цепь «жизни книги»: «сформирование ее», проявление перед публикой, «книжное обращение и распространение книги» и «вхождение в сообщество», добавил анализ факторов, которые сопутствуют развитию книжной культуры, относя к ним состояние культуры, степень умственного и нравственного развития и образования общества и личности, исторический момент, личность автора, издателя, торговца, политическое состояние государства и общества, степень насыщенности книжного рынка, состояние торговли и промышленности, емкость рынка (количество типографий, издательств), состояние книгопечатания и техники, историческая традиция, состояние и развитие устного и печатного слова.

Именно в рамках данного подхода уже в дальнейшем идут основные изыскания понятийного состава книжной культуры, которая долго терминологически отождествляется и с книжным делом, и с «книжным искусством», «культурой книги», «искусством книги», «типографским делом», соединяется с литературным процессом и другими понятиями, сопряженными с книжной культурой. В самом начале формирования этого направления (XIX первая треть XXв.) книжная культура понимается как «искусства книгопечатания» или «типографское искусство», на что указывает видный исследователь книжной культуры, руководитель Научного центра исследований книжной культуры, профессор, член-корреспондент РАН В.И. Васильев [6].

В дальнейшем (первая треть - конец XX в.) формируются понятия «искусство книги» («книжное искусство», «искусство оформления книги»), «издательская культура», «культура книги» («культура издания книги», «культура производства книги») и собственно «книжная культура» («народная книжная культура», «славянская книжная культура», «эпиграфика и книжная культура», «региональная книжная культура», «старообрядческая 
книжная культура» и др.), что в 20-70-х годах XX века связано с именами А.А. Сидорова, М.И. Слуховского, В.А. Фаворского, Д.А. Шмаринова, В.Н. Ляхова, Е.Л. Немировского, а в последней трети XX века - с именами И.Е. Баренбаума, А.М. Панченко, С.А. Пайчадзе, В.И. Гульчинского и др.

Обзор трудов этих ученых показал, что к единой дефиниции ученые не приходят, но все же в их трудах формируется представление о книжной культуре как отдельном культурном феномене, которое требует изучения как часть культуры общества в традициях системного и культурологического подходов.

Отметим, что одним из первых в России, исследуя историю книжной культуры, понятие определил М.И. Слуховский. Он употребил это понятие как «понимание русскими людьми общественно-политической роли книги и библиотеки, создание и распространение книг и библиотек, пользование книгой и библиотекой» $[26 ; 7]$.

Советский книговед А.А. Сидоров в исследовании, посвященном истории русской книги, связывает культуру книги, имея ввиду книжную культуру в целом, с культурой определенного периода, говорит о неотделимости истории книжного дела от истории культуры, истории развития общества в целом, и вместе с тем говоря о необходимости «уметь и увидеть в книге ее неповторимо индивидуальные черты» [27; 10]. Профессор А.А. Сидоров, характеризуя состав и структуру книжной культуры, говорит о том, что она является частью «общественной культуры определенного периода», также утверждая, что «изучение книги должно сочетаться с изучением людей, читающих книгу, и условий, при которых книга читалась».

Известный советский библиограф В.И. Гульчинский тоже говорит о книжной культуре как сегменте культуры общества, фактически раскрывает границы понятия, рассматривая ее как «исторически обусловленную общественную деятельность по созданию, распространению, потреблению и хранению книги и других носителей информации». [10; 12]. Книжную культуру он связывает с культурой общества и говорит о необходимости учитывать ту «творческую деятельность, направленную на «познание книги», книжного дела и самого книговедения».

Последнюю мысль поддерживает в своих исследованиях, опубликованных ранее доклада Гульчинского, и И.Е. Баренбаум, который определяет книжную культуру как область знания и основной задачей видит изучение читательских интересов, круг чтения отдельных лиц и целых социальных слоев» [2; 6] определение тех книжных источников, которые имеют популярность в тот или иной исторический период. Важно для ученого и формирование читательских интересов, факторы, влияющие на отношение читателя к книге, влияние чтения на формирование мировоззрения, что видится вполне в духе традиций, заложенных М.Н. Куфаевым и Н.А. Рубакиным.

По мнению уважаемого отечественного книговеда С.А. Пайчадзе, книжная культура представляет собой «уровень, достигнутый книжным делом, в сочетании с исторически сложившимися традициями отношения народа к книге в данной конкретной стране или регионе на определенной ступени развития общества» [23; 4], при изучении книжной культуры он обращал внимание на региональный аспект. Ярким примером такого регионального подхода является многотомный коллективный труд книговедов Сибири «Очерки истории книжной культуры Сибири и Дальнего Востока» [23]. В этом ключе проводились исследования Г.М. Агеевой, Л.С. Лукьяновой, В.В. Пугачевым, Ю.В. Жуковой и др. Важность регионального аспекта в исследовании отмечает и В.В. Добровольский, характеризуя книжную культуру как научную категорию он говорит о ней как одном из компонентов национальной культуры, выделяя, что «национальная книжная культура складывается на основе национального самосознания, национальной самоидентификации» $[11 ; 48]$.

В.И. Васильев, которого преимущественно интересуют вопросы истории книжной культуры, не давая своей дефиниции понятию, все же подробно рассматривает многоуровневую систему книжной культуры, включая в ее составные компоненты культуру книги, культуру ее распространения в обществе и культуру чтения, отмечая, что «сегодня можно говорить о книжной культуре как синтезе духовной культуры и искусства, продукте духовной культуры и духовного производства, материальной культуры и материального производства» [7].

Интерес к дефиниции понятия книжная культура, определению места книги в современном обществе, ее возможностей социокультурного воспроизводства возрождается и в последние десятилетия. В условиях бурного развития информационно-коммуникационных технологий и одновременно активного их проникновения в книжное дело немало споров ведется об электронной книге, о ее месте в современном книговедении, о книге в Интернете, о будущем книги и чтения в целом. Еще в 1960-е годы появляется направление, начало которому было положено канадским социологом и литературоведом Хербертом Маршаллом Маклюэном, опубликовавшим книгу с метафорическим названием «Галактика Гутенберга», сопроводив его подзаголовком «Сотворение человека печатной культуры». Книга утверждает тезис исчерпанности бумажной книжной культуры, неизбежность «заката» эры печатной книги и наступления электронной эры, которая приведет к созданию новой цивилизации в форме «глобальной деревни». Основной тезис культурфилософской концепции массовой коммуникации Маршалла Маклюэна состоит в том, что 
письменность и печать ответственны за появление и развитие западного типа культуры - книжной культуры, которая характеризуется линейным способом передачи и освоения информации, основанном на односторонне-визуализированном восприятии. А человек всегда создавая себе «орудия труда», которые по сути является продолжением его самого, стремится заменить ими те функций, которые он некогда выполнял с помощью своего тела. И книга - это тоже орудие, инструмент увеличения памяти человека и передачи его опыта. Но со временем происходят радикальные изменения в способах повседневной человеческой деятельности, и книга тоже, в свою очередь, влияет на культуру и формирует новый тип человека, создавая предпосылки для появления более эффективного и технологически ещё более сложного устройства усиления человеческой памяти и интеллекта - компьютера, который и вытеснит в конечном счете книгу, как считает Маклюэн, вернув человеку первобытное мифологически-образное ощущение жизни, которое, как он считает не характеризуется односторонностью, и таким образом сформируется новый тип культуры - медиа-культуры [21].

Известный итальянский писатель, семиолог и исследователь культуры У. Эко в своих «Шести прогулках в литературных лесах» не согласен с этой позицией, он считает важным, что именно «в литературном тексте читателю постоянно приходится выбирать», а «иногда повествователь оставляет за нами право домыслить» [32; 14]. Это и есть процесс культурной коммуникации, которая так важна человеку. В своей популярной лекции «От Интернета к Гутенбергу: текст и гипертекст» У. Эко говорит, что электронные варианты носителей книг реально могут вытеснить книгу бумажную, однако в поисках живых путей книга найдет возможности «использования» средств массовой информации, потому «не надо противопоставлять визуальную и вербальную коммуникации, а надо совершенствовать и ту, и эту» [31]. Однако упадок книжной культуры как отказ от серьезного чтения грозит культуре последствиями и возвращает нас, по мнению У. Эко, в состояние варварства, редуцируя наши речевые и письменные навыки и сводя письмо к sms, а живой диалог к записям в социальных сетях. Он утверждает, что современное общество расщепляется на два класса: тех, кто смотрит телевидение, то есть получает готовые образы и суждения о мире, без возможности критического отбора предлагаемой информации, и тех, кто смотрит на экран компьютера, то есть обладает умением отбирать и обрабатывать информацию. Современные поколения уже мало смотрят телевидение, но сильно подвержены клиповому мышлению и готовы получать фейковую информацию, не отличая ее от достоверной, ведь это уме- ние предполагает «читательскую грамотность» и «книжную культуру».

\section{Зак^ючение}

Сегодня в отечественной науке уже имеются исследования, делающие попытки нового взгляда на книжную культуру. Переосмысление процессов, происходящих в книжной культуре, «переворот в мире чтения» [29; 11], связанный с развитием информационного общества, появление экранного формата книги требуют дополнения ранее сложившихся подходов к его научному изучению. Безусловно, электронный текст сегодня занимает особое место в системе книжной культуры и осмысление понятия цифровая (или электронная) книга и цифровая (или электронная) книжная культура уже находит свое место в числе современных научных подходов к изучению книжной культуры, но это предмет отдельного исследования.

Очевидно, что наука встала перед необходимостью создания своеобразного методологического инструментария и подхода к изучению книжной культуры. Увидеть сложное явление культуры более структурировано и полно, на наш взгляд, позволяет библиокультурология, выступающая комплексной научной отраслью и являющаяся методологическим фундаментом и предметом изучения книжной культуры» [5]. Если мы исходим из того, что культура - это освоенный и овеществленный опыт человеческой деятельности, а он, в свою очередь, представляет собой знания и умения, которые передаются от поколения поколению и представляют собой ту программу действий, которые мы закрепляем для взаимодействия и сосуществования в обществе и решения всевозможных жизненных ситуаций, мы можем говорить, что книжная культура представляет собой «интегративную характеристику культурного процесса, включающую единство как непосредственной деятельности людей по передаче-освоению в знаковой форме накопленного социального опыта, так и результаты этой деятельности, закрепленные в виде знаний, умений, навыков, компетенций и специфических институтов такой передачи в пространстве и во времени от одного поколения к другому» [5; 170]. Такое определение, данное в ключе изучения книжной культуры с позиции библиокультурологии, в должной мере, как нам видится, отражает, с одной стороны, современную ситуацию с трансформацией носителя накопленного культурного опыта, накопленного в знаковой форме, и не ограничивает книжную культуру рамками собственно бумажной книги (или другим конкретным носителем информации), с другой стороны, делает важный акцент на диалогической природе процесса культуротворчества. 


\section{ЛИТЕРАТУРА}

1. Аверинцев С.С. Попытки объясниться: беседы о культуре [Электронный ресурс]. URL: https://predanie.ru/book/72351-popytki-obyasnitsya-besedy-0kulture/ (дата обращения 20.01.2021).

2. Баренбаум И.Е. История читателя как социологическая и книговедческая проблема // История русского читателя / науч. ред. И.Е. Баренаум. Л.: ЛГИК, 1973. Вып. 1. С. 5-19.

3. Бахтин М.М. Эстетика словесного творчества // сост. С.Г. Бочаров, примеч. С.С. Аверинцева, С.Г. Бочарова. М.: Искусство, 1986. 445 с.

4. Беловицкая А.А. Книговедение. Общее книговедение [Электронный ресурс]. URL: http://hi-edu.ru/e-books/xbook991/01/part-004.htm (дата 0бращение 10.01.2021)

5. Бенин В.Л., Гильмиянова Р.А., Жукова Е.Д. Библиокультурология: теория и практика: монография - Уфа: Башкирский государственный педагогический университет, 2015. С. 170.

6. Буслаев Ф И. 0 литературе: Исследования; Статьи / сост., вступ. статья, примеч. Э. Афанасьева. М.: Худож. лит., 1990. 512 с.

7. Васильев В.И. Книжная культура в отечественной истории: теоретические и историко-книговедческие аспекты (XVII - начало XXI в.) : специальности 05.25 .03 «Библиотековедение, библиографоведение и книговедение» и 07.00.02 «0течественная история» [Электронный ресурс] // Автореферат диссертации на соискание доктора исторических наук. Научный совет РАН «История мировой культуры». M., 2005. 101 c. URL: http://tekhnosfera.com/ view/462258/a\#?page=20 (дата обращения 20.01.2021).

8. Вокресенский А.К. Информация и книга: Культурологические и гносеологические аспекты [Электронный ресурс]. URL: https://cyberleninka.ru/article/n/ informatsiya-i-kniga-kulturologicheskie-i-gnoseologicheskie-aspekty (дата обращения 20.01.2021).

9. Гречихин А.А. Современные проблемы типологии книги. - Воронеж: Изд-во Воронеж. ун-та, 1989. 246 с.

10. Гульчинский В.И. Книжная культура и ее источники // Шестая Всесоюзная научная конференция по проблемам книговедения. М., 1988. С. 11-13.

11. Добровольский В.В. «Книжная культура» как научная категория // Книга и мировая цивилизация. М.: Наука, 2004. Т. 1. С. 47-49.

12. Иванова Л.Г. Книжная культура студента-гуманитария: специальность 24.00.01 Теория и история культуры : диссертация на соискание ученой степени кандидата культуроллогии. Шуя, 2011. С. 34.

13. Книга: Энциклопедия / редкол.: И.Е. Баренбаум, А.А. Беловицкая, А.А., Говоров [и др.]. М. : Большая российская энциклопедия, 1998.800 с.

14. Книговедение: энциклопедический словарь / ред. коллегия: Н.М. Сикорский (гл. ред.) [и др]. М.: Сов. Энциклопедия, 1982. 664 с.

15. Куфаев М.Н. Избранное. М.: Книга, 1981. 176 с.

16. Лихачев Д.С. Задачи изучения связи рукописной книги и печатной // Рукописная и печатная книга: Сборник / Редколлегия: А.А. Сидоров (пред.) [и др.]. М.: Наука, 1975. С. 10.

17. Лихачев, Д.С. Избранные труды: в 3-х томах [Электронный ресурс]. URL: https://www.lihachev.ru/lihachev/bibliografiya/4728/ (дата обращения: 20.01.2021).

18. Лосев А.Ф. История античной эстетики. М., 1988.

19. Лотман Ю.М. Статьи по семиотике и топологии культуры / Предисл. С.М. Даниэля, сост. Р. Г. Григорьва. Спб.: Академический проект, 2002. 543 с. [Электронный ресурc]. URL: http://teatr-lib.ru/Library/Lotman/statjy/ (дата обращения: 29.01.2021)

20. Любите читать!: Письмо 22-е // Лихачев Д.С. Письма о добром и прекрасном. М., 1988. С. 95-99.

21. Маклюэн Г.М. Понимание медиа. Внешние расширения человека. Кучково поле, 2018. 464 с. / перевод с английского В.Г. Николаева. М. : Жуковский: «КАНОН-пресс-Ц», «Кучково поле», 2003. 464 с.

22. Отле П. Библиотека, библиография, документация: Избранные труды пионера информатики. М.: ФАИР-Пресс, Пашков дом, 2004. 348 с.

23. Очерки истории книжной культуры Сибири и Дальнего Востока. Т. 1. Конец XVIII - середина 90-х годов XIX века / отв. ред. В.Н. Волкова. Новосибирск, 2000.316c.

24. Пайчадзе С.А. Новосибирск - центр региональных исследований в области книговедения / С.А. Пайчадзе // Вопросы краеведения Новосибирска и Новосибирской обл. / под ред. Л.М. Горюшкина, В.А. Зверева. Новосибирск: Изд-во СО РАН: ОИГГМ, 1997. С. 27-33.

25. Рубакин Н.А. Избранное. В 2-х т. Т. 1. М.: Книга, 1975. 224 с.

26. Слуховский М.И. Из истории книжной культуры России. Старорусская книга в международных культурных связях. М.: Просвещение, 1964. 244 с.

27. Сидоров А.А. Об исследовательской работе по истории русской книги // Книга в России до середины ХІХ века. Л.: Наука. 1978. С.10.

28. Столяров Ю.Н. Документология: учеб. пособие / Ю.Н. Столяров; Моск. гос. ун-т культуры и искусств, Орл. гос. ин-т искусств и культуры. - Орёл: Горизонт, 2013. $370 \mathrm{C}$

29. Сметанникова Н.Н. Ведущие зарубежные теории чтения XX века и их воплощение в методологии и методиках обучения // Чтение. XXI век: коллективная монография / научн. ред.-сост. В.Я. Аскарова. Челяб. гос. акад. культуры и искусств. Челябинск, 2014. С. 11.

30. Швецова-Водка Г.Н. Общая теория документа и книги: учеб. пособие / Г.Н. Швецова-Водка. М.: Рыбари; К.: Знания, 2009. 487 с.

31. Эко У. От Интернета к Гутенбергу: текст и гипертекст [Электронный ресурс]. - URL: http://umbertoeco.ru/ot-interneta-k-gutenbergu-tekst-i-gipertekst/ (дата обращения 24.01.201).

32. Эко У. Шесть прогулок в литературных лесах / пер. с англ. А. Глебовской. СПб.: «Симпозиум», 2007. 285 с.

(c) Асфандиярова Альфия Рашитовна (cbs-direktor@mail.ru).

Журнал «Современная наука: актуальные проблемы теории и практики» 